\title{
The experience of caring for a dying client with intellectual disabilities. A qualitative study with direct-caregivers*
}

\author{
Hanneke J. W. Bulsink ${ }^{1 \#}$, Jean Jacques Georges ${ }^{2}$ \\ ${ }^{1}$ Department Clinical Health Sciences, University Utrecht, Medical Services, Fatima Zorg, The Netherlands \\ ${ }^{2}$ University of Applied Sciences, Utrecht, The Netherlands \\ Email: "hbulsink@,fatimazorg.nl
}

Received 9 April 2013; revised 8 November 2013; accepted 22 November 2013

Copyright (C) 2013 Hanneke J. W. Bulsink, Jean Jacques Georges. This is an open access article distributed under the Creative Commons Attribution License, which permits unrestricted use, distribution, and reproduction in any medium, provided the original work is properly cited.

\begin{abstract}
Background: Caregivers experience problems when caring for people with intellectual disabilities who are terminally ill. Aim: The aim of this study is to gain a deeper understanding of the experience of the caregiver when caring for a person with intellectual disabilities who is terminally ill and what influences this experience. Design: A qualitative research was carried out following the principles of Grounded Theory (GT) method, through fifteen interviews with caregivers in a living facility with continuous care. Results: The results show how caregivers strive to create meaningful moments for their client during the last period of his life. Since very few of the clients can clearly express their wishes and feelings, continuous observation is required of the caregivers for the interpretation of small signals of their clients. In that way, the appropriateness of their actions can be made certain. The results show that because of their involvement, caregivers are able to recognize clients' signals. When a client is dying, the special atmosphere created on the ward contributes to coping with the situation and a positive experience. Conclusion: Direct-caregivers caring for a client with an intellectual disability who is terminally ill, experience an intense period of insecurity and also a special period meaningful when caring a dying client with intellectual disabilities. Their relationship with the client makes them to be more able to strive for client's comfort. The results also show that some factors such as enough staff, clear and open communication with the physician and support of the manager contribute to the quality of palliative care on the ward.
\end{abstract}

"Conflict of interest statement: the authors declare that there is no conflict of interest.

"Corresponding author.
Keywords: Dying; Intellectual Disability; Palliative Care; Caregivers; Experiences

\section{INTRODUCTION}

Because of increased longevity, formal caregivers taking care of intellectual disabled (ID) persons get more and more involved with clients who are terminally ill. It is expected that the number of older persons ( $>65$ years) with ID will double by 2020 [1], therefore an increasing number of ID persons will be confronted with life threatening diseases like cancer, heart issues and chronic pulmonary diseases [2].

Most studies about the end of life care for people with intellectual disabilities are directed on the palliative stage [3-6], but not the terminal stage until the death of the client.

However, an irreversible illness could begin insidiously in people with intellectual disability resulting suddenly in a short observable period of being terminally ill and dying within a short period $[7,8]$. It is known that the start of the palliative stage is not easy to determine in persons with intellectual disabilities [7]. Thereby making medical and life-changing decisions may be difficult.

A literature review about palliative care in all people with intellectual disabilities shows that caregivers experience problems with signals of sickness and pain (selfreporting is difficult, if not impossible), ethical issues, care giving and planning, and a lack of knowledge in caregivers: a lack of knowledge of persons with ID of professionals experience in palliative care and a lack of knowledge of palliative care of services experiences in intellectual disability [8]. Caregivers do not realize how they could benefit from training despite of this lack of knowledge [9].

Issues also arise from making decisions in the end of life care, especially when caregivers do not agree with the 
medical practitioner or with the wishes of the client [8].

Several research reports describe that by the involvement and intense relation of caregivers with their client, caregivers are able to detect minimal changes in physical condition and behavior, but also may lose the capacity to be still objective about the caring situation $[6,10,11]$.

Study results show that experience problems of caregivers related to withdrawing nutrition and medication [4, 6] and that they feel anxious because of being confronted with the impending death of their client, not being sure of doing the right things when caring for the client [12]. However, solidarity from coworkers as well as regular visits from medical practitioners is comforting [12].

Previous studies are mostly case studies and quasiexperimental research focusing on practical issues such as training needs, communication with clients and ethical issues. However, studies directed on describing the experience of caregivers of clients with intellectual disabilities at the end of their life are needed in order to develop palliative care for this specific population further.

The aim of this study is to gain a deeper understanding of the experience of the caregiver when caring for a person with intellectual disabilities who is terminally ill and what influences this experience. The results will contribute to improving education and support for direct caregivers and consequently improving care in the last phase of life of people with intellectual disabilities.

\section{METHODS}

A qualitative research following the principles of Grounded Theory (GT) method was carried out. The study took place in a setting for people with intellectual disabilities in Eastern Netherlands from January 2011 to June 2011. A purposeful sample was drawn from direct-caregivers who had experience with caring for terminally ill clients in 2010 or 2011 . Trainees were excluded because of their short stay in this setting, as well as direct-caregivers with whom the investigator had worked with to maintain objectivity [13].

After consent for the study was obtained executives brought the investigator in contact with experienced caregivers in order to inform them about the study and ask them participation. Caregivers who were willing to participate signed an informed consent.

In order to first gain global insight into the experience of caregivers the initial sampling was directed on achieving enough variation on gender, age, experience and workplace of the respondent [14]. During a second stage sampling was based on the results of analyses of the first 5 interviews and more theoretical driven. One respondent who took care of a client who died in 2007 was approached, because in order to get more detailed information about the peculiarity of the group and the mild intellectual disability of the client. Furthermore a choice was made to approach caregivers form a specific workplace because of the potential richness of the experience they had had, and also to interview caregivers who were working in nightshift and accessible services.

\section{DATA COLLECTION}

Semi structured interviews were carried out with an interview guide [14]. The interview guide was developed after an initial literature review and directed on the following topics: relation with the client, care giving experience, withdrawing nutrition, client transition to the terminal stage, time after death, caring for inmates. The appropriateness of questions was evaluated with the study supervisor (JJG) after each three interviews and adjusted when necessary in order to gain more insights on the developing concept [15], f.e "create meaningful moments" and "doing everything you can".

Issues in the last interview guide were: experience with terminal care, ethical issues, positive experience, relation with the client, feeling doubt about the way the client feels, course of the illness, meaning of terminal care and care in general.

Each respondent was interviewed one time; interviews took 35 to 70 minutes $($ mean $=51)$ thirteen interviews were held on the workplace and two at the home of the caregiver.

Interviews were recorded and transcribed completely, and next anonymized. The source code was saved in an encrypted file [15].

\section{DATA ANALYSES}

Data analyses consisted of constant comparison of text fragments, codes and categories with each other considering similarities and differences [13]. During the first four interviews each sentence was coded, after that text fragments were coded during the remaining interviews. After those four interviews with open codes axial coding was started. Each code was combined with similar codes into categories and their content according to the investigator described and questions were raised for the next interviews.

After the eleventh interview coding became selective and directed on describing the relations between different categories [14]. A full description of categories and relation between the categories was made after analyse of the last interview and control of the findings in the previous interviews and codes and critical discussion with the supervisor (JJG) about the development of insights and strength of recurring patterns.

\section{RELIABILITY OF RESULTS}

The researcher was prepared for data collection with training and an interview test. A contact summary sheet 
and profile of respondent was written after each interview, which consisted of observations, impressions and features of the respondent directed on reflections of the investigator.

We strove to optimize objectivity by paying much attention to different possibilities of interpretation during the study, by a long period of open coding of transcripts and regular critical discussions with the supervisor during the study.

The supervisor analyzed two interviews independently and differences about codes and insights were discussed. In order to analyse, compare and retrieve data more systematically software Win Max package for qualitative data analyse was used [16].

During the phase of axial coding attention was paid to clearly described categories and when necessary questions about missing information missing or directed on gaining confirmation were asked during the following interviews.

Furthermore several kind of memos were written during the study, memos describing reflections of the investigator about the own experience as researcher in this specific situation and memos describing the development of the several categories.

Finally, the investigator and supervisor searched for replication of concepts in the data by selection of respondents during sampling and adjustment of the interview guide.

\section{RESULTS}

The fifteen respondents included in the study describe their experience of caring for twenty clients. Fourteen respondents were female; the average years of work experience were 25 years. Twelve respondents had a nursing education three had other education in social sector. Fifteen clients had a severe or profound mental retardation [17]. Features are shown in Table 1.

The results are directed at describing the process of caring for a dying person with an intellectual disability during the palliative phase; the central themes found has been described as: seeking reassurance for own actions and creating meaningful moments. Caring for persons with intellectual disabilities means observation, analyzing, interpreting and acting on small signals from clients. In the last phase of life this happens even more frequently and intensively. Direct-caregivers act in this phase deliberately and are more alert to small signals of the client, because they want to be meaningful to the client while they can. They have to rely on their own interpretations to give good care, what makes them emotionally involved (see Figure 1).

"Yes that gave me really something actually yes. Even if it was with a massage for example, and if you could see then that he liked it for that moment and then... that
Table 1. Characteristics of respondents and clients.

\begin{tabular}{|c|c|}
\hline Characteristics respondents & $\mathbf{n}=\mathbf{1 5}$ \\
\hline Age in years median (range) & $50(19-61)$ \\
\hline Gender (woman/\%) & $14(93 \%)$ \\
\hline Work experience in years & $25(3-40)$ \\
\hline Years taken care of the client median (range) & $2(0-23)$ \\
\hline \multicolumn{2}{|l|}{ Education } \\
\hline Intellectual disability nurse & 8 \\
\hline $\begin{array}{l}\text { Secondary vocational education - middle } \\
\text { management training (social work) }\end{array}$ & 1 \\
\hline $\begin{array}{l}\text { Secondary vocational education - middle } \\
\text { management training (nursing) or in training }\end{array}$ & 4 \\
\hline $\begin{array}{l}\text { Secondary vocational education - } \\
\text { professional training or less }\end{array}$ & 2 \\
\hline \multicolumn{2}{|l|}{ Function } \\
\hline Accessible services & 2 \\
\hline Nightshift & 2 \\
\hline Coordinating direct-caregiver & 6 \\
\hline Direct-caregiver & 3 \\
\hline Raid direct-caregiver & 1 \\
\hline Student & 1 \\
\hline $\begin{array}{c}\text { Type of group (according to clustering) } \\
\text { Guidance }{ }^{1} \\
\text { Guidance and caring }{ }^{2} \\
\text { Caring } \\
\text { Nightshift } \\
\text { Stand-by nurse }\end{array}$ & $\begin{array}{l}1 \\
5 \\
5 \\
2 \\
2\end{array}$ \\
\hline $\begin{array}{l}\text { Location of the group } \\
\text { Field setting } \\
\text { Outside the setting }\end{array}$ & $\begin{array}{c}14 \\
1\end{array}$ \\
\hline $\begin{array}{l}\text { Time between death client and interview } \\
\text { in months median (range) }\end{array}$ & 4 (still alive -300 ) \\
\hline Characteristics clients & $\mathbf{N}=\mathbf{2 0}$ \\
\hline Age in years median (range) & $53.5(7-74)$ \\
\hline Gender woman $(\%)$ & $11(55 \%)$ \\
\hline \multicolumn{2}{|l|}{ Level of developmental disorder [17] } \\
\hline $\begin{array}{l}\text { Moderate mental retardation } \\
\text { Severe mental retardation }\end{array}$ & $\begin{array}{l}2 \\
7\end{array}$ \\
\hline Profound mental retardation & 8 \\
\hline Unknown & 2 \\
\hline Not innate & 1 \\
\hline
\end{tabular}

${ }^{1}$ Guidance means that clients can care for themselves but need guidance with that through behavioural problems and disability, mostly moderate to severe mental retardation. ${ }^{2}$ Guidance and caring means that clients need help with daily care activities, but they can communicate, mostly severe mental retardation. ${ }^{3}$ Caring means that clients need caregivers to take over their care. Mostly profound mental retardation. 


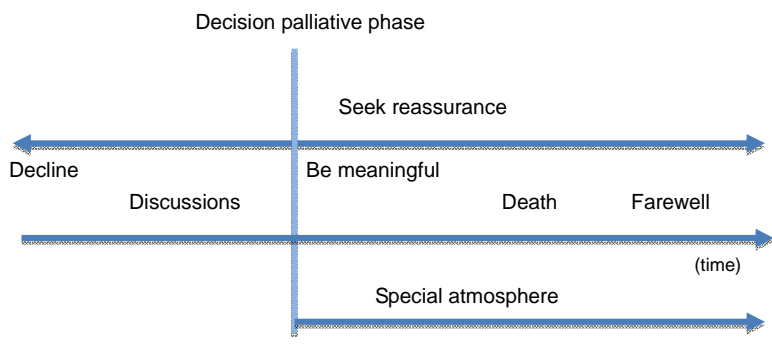

Involvement with the client

Relation with the client Manner of death Experience Culture in a team

Figure 1. Representation of central themes.

is why you did it." nr. 10.

\subsection{Seeking Reassurance for Own Actions}

If the client is able to make his own choice, then directcaregivers indicated it was easier to estimate the signals and advocate for the client. Caregivers described that it could be difficult to gain insight into the real wishes and needs of a client and often doubt whether they interpret the signals of their client such as pain, agitation, fear, and respiratory depression correctly.

"What means that yelling than, right? Does he do it because it is his attribute or does he yell of pain? While we didn't assume it was pain. But you never know." nr. 6.

The intellectual disability can make it impossible to find out what is bothering the client. In a consultation with the medical practitioner they consider how a client could become less agitated and medication is given. Caregivers feel frustrated when the cooperation with medical practitioners is not working well enough; through what they feel the client still is not comfortable.

Direct-caregivers describe that it is very important to them to be sure they have done everything they could for their client, some of them even let appear that by this it was easier to cope with the death of their client.

"We did everything possible. She had a very turbulent life, so I thought, yes it was all right this way". nr. 4.

After death of a client is seems important for caregivers to spend time together and to share their experience and speak about their feelings within the team. By evaluating the care process and finding reassurance from colleagues' caregivers and family could reach disclosure.

"They said that so beautiful in church: 'they are named leaders they are not, they are angels' her sister-in-law said (...) Also that you are doing well, because that is important to me right." nr. 15.

\subsection{To Be Confronted with the Decline of Their Client}

When the client declines and his basic functions deteriorate it is not possible anymore to have contact with the client, caregivers told that because of this they find it to be sure about how to care in a good way for their client.

Caregivers are gradually more and more confronted with Ill-conditioned periods of their client. Sometimes even if there is no apparent gradual decline direct-caregivers tell they feel there is something wrong with the client.

Caregivers describe that for some clients living is no longer worthy during the last phase of his life because of seizures, pain and discomfort.

"Yes these children were just so... yes I found it actually unbearable, yes unbearable suffering, yes... you don't know what they feel, but it is just no longer worthy living." nr. 10.

The gradual decline gives direct-caregiver time to get used to the idea that the client will die and to accept the inevitable. The nearing death is than experienced as "the best thing for the client". For direct-caregivers it can be hard to see the condition of the client get worse.

"so you cope with a piece of impotence, you would want her to get better, while if you think rationally, you know it is not possible, but there is your own feeling too right?" nr. 2.

\subsection{Having to Make Medical Decisions about the End of Life}

In the period of the clients' decline a do-not-resuscitate (DNR) declaration is discussed. Mostly an agreement is achieved directed on restraining medical examinations and treatments in order to avoid to burden the client. Because of the restriction of medical examination it could happen that the prognosis is unclear and that difficulties arise about the way the client should be treated medically or about withholding treatment.

"Why do you give laxatives while nothing is coming out, is there something else in the way, do you have to make a scan or an ultrasound to see if you can do something about it, or is that no longer necessary, is it too far?" nr. 13.

When the suffering of a client is becoming unbearable for the client and the team is becoming certain that it is not possible anymore to lessen the suffering of the client the decision is taken to initiate palliative sedation with Morphine and/or Dormicum pump in consultation with family, direct-caregivers, medical practitioner and a palliative care team. The caregivers see the beginning of palliative sedation as the start of the terminal phase.

Almost all respondents describe that family and caregivers because of not understanding very well the indication and working of palliative sedation, express their wish of a fast dying process. In such situation respondents find it important that a medical practitioner gives a clear explanation about palliative sedation.

Some direct-caregivers also described that it is very 
hard to be confronted with withdrawing food when client are still conscious, because they than feel that they let the client starve to death. Whenever this happen they need to talk about it with each other and share their feelings with the medical practitioner to make sure no one is caring for the client against their own values.

\subsection{Creating Meaningful Moments}

Reducing pain has a high priority for direct-caregivers. They describe that nothing is more frustrating than to see the client suffering from pain; therefore they try to prevent this from happening with everything in their power.

"You make sure that they have no pain. That is indisputable that you make sure that, as long as they have no pain." nr. 5.

They described that it is very important for them to be sure that everything is done to keep the client as comfortable as possible, for example by creating a relaxing sphere in the room with a light, music or snoezel attributes. The direct-caregivers want to give extra care, like holding a client's hand, talking to the client, giving a massage, singing a song (together), humidifying their lips, giving face care or stroking the head. They strive "to be with" the client in the last phase, visiting him more often and being more alert to signals.

Direct-caregivers told they get frustrated when they do not have enough time to care properly for their client, or when they than have to share their attention with other clients on the ward.

"What hurts me the most is that you just have to do it next to everything else. As I think, someone is in the last phase of his life right, you just want to sit next to the client and take your time for this moment." nr. 14.

Respondents indicate that when the client's bedroom is far away from the living area, they provide for a bedroom nearby so they can observe the client. They make sure they use every moment they can. For example take a client outside when she is awake. Caregivers want that the client feel safe and not lonely. Therefore they use each moment to let the client be meaningful to them and to say their goodbyes.

"That hurts a little, well actually you would have, you would have to sing with him, or let him take a long bath or..." nr. 6.

Because of the relation that the direct-caregiver took on with the client, she is emotionally involved with the client. The intensity of the emotions and the degree of the involvement with the client is influenced in several ways and distinct the urge to create meaningful moments with this client.

\subsubsection{Relation with the Client}

Direct-caregivers often speak of a special connection with a client, which seems to mean that they feel more involved with a client than with another client.

Such a "special connection" seems to be related to the length of the relationship, a serious event between directcaregiver and client, the intense care the client needs and the contact with the family of the client cause this connection. Some direct-caregivers, who also are the coordinating direct-caregiver also describe to have such a special connection because of the responsibility they have for the client.

\subsubsection{Being Confronted with Client's Death}

The abrupt death of a client cause a lot of emotions on direct-caregivers, because they than find it difficult to get used to the idea of dying and cannot create the last meaningful moments. Also the sort of illness can influence this process, if a client does not die of old age it can be hard to manage, for example dying of cancer. Caregivers also describe it's a bad experience to be confronted with the death of a child, which mostly has a bigger impact on direct-caregivers than the death of an aging client.

\subsubsection{Being Experienced}

Having more experience with caring for dying clients seems to help caregivers to better see how to care adequately for a dying client and to be more confident to care for the client. Caregivers told for example that because they feel connected to the client they could put the dying process into perspective and also better recognize signals of the impending death. The first time someone is confronted with experiences of a death; it can be a difficult experience.

\subsubsection{Culture in a Team}

Between teams there exists differences in culture and practice related to the intensity of the involvement. Out standers of teams, like accessible services, think that direct-caregivers involvement and heavy emotions can prevent them to stay professional and accomplish their tasks. According to one respondent it is good to make some agreements in a team about the degree of involvement of everyone in caring for this client. Some caregivers described they need support from executives or colleagues to act professional in case of a clients death.

\subsection{Being There at the Moment of Death}

Several direct-caregivers indicate that it is special to be there when the client dies. It contributes to a positive experience. The direct-caregiver is less emotional then.

"Yes that makes it different, yes I think so. Yes because then um you sit with him? It actually and you finish it and... it is easier to process. It is easier to handle." nr. 6.

It is experienced differently when a client dies alone. Several respondents indicate it as a shortcoming of care, because they could not do anything for the client when it 
was still possible. Others do not see it as a problem; they state that the client has to have the chance to die alone.

\subsection{Being Able to Close the Relation}

Most of direct-caregivers find it meaningful to care for the deceased themselves. Passing of a deceased client makes it possible to share a last meaningful moment together.

If the client dies they have to end the relation they had. They can do this by saying their farewell and to visit the deceased client or by commemorating the client with his own special peculiarities. At least direct-caregivers attend the funeral and prepare it together with colleagues and family. Direct-caregivers indicate that by the final farewell they become emotional. Saying farewell together contributes to the special atmosphere at that moment.

"When he left us, when the undertakers took him to his parents' home and the medical practitioner, and me and that colleague of me stood there crying at the doorstep." nr. 10 .

\subsection{Special Atmosphere}

The atmosphere in the last phase makes the death acceptable despite the grief. Solidarity arises when direct-caregivers work together with the medical practitioner, family and perhaps other disciplines to accomplish optimal care and a comfortable client. This takes place in the phase prior to death. Solidarity can also arise with the family of the client through the involvement between them. A respondent describes this as a gift if you can comfort each other.

"But yes I thought wow, wow, how beautiful. Together in his red plaid in, we put him nice in his coffin, nice where he was always in lying in, you know. So safe and yes, yes. But that was nice than..." nr. 12.

Sometimes caregivers experience it as a burden to support client's family and colleagues. They find it difficult to act professionally as they mourn the client.

Working after the death of a client is important for some direct-caregivers in order to create a good atmosphere by talking and remembering with colleagues and giving support to each other. Direct-caregivers then can set their own boundaries and there is space for their insecurities. It is necessary that they have time to do this while they are on the job.

\section{DISCUSSION}

This study based on a grounded theory approach was directed on gaining a deeper understanding of the experience of the caregiver when caring for a person with intellectual disabilities who is terminally ill.

The results show that direct-caregivers, caring for a client create meaningful moments with the client in the last period of his life. They seek reassurance for their actions, by continuous observation and interpretation of the clients' small signals, because the client can't tell how he feels. The special atmosphere created on the ward were someone is dying contributes to a positive experience. Because of their relation with the client and their emotional involvement caregivers are able to recognize the clients' signals.

This study focuses on caregivers of clients with a profound or severe intellectual disability in a living facility with twenty-four hour care. The respondents in this study have all but two a nursing background. This should be taken into consideration when interpreting the results, given the fact that there are also group homes placed in the community, with caregivers trained for social work and clients with mild to moderate retardation (55.000 persons versus 60.000 persons with severe or profound retardation) [18]. It is possible that the interviews lack of objectivity because the investigator was working as direct-caregiver with the same client population during the study, however measure to avoid threats on the objectivity have been taken by making a review of the interview and frequent discussions about this issue with the supervisor.

It is also possible that saturation has not been achieved for all main themes described in the results as only fifteen interviews were held, however the last two interviews have not lead to discover new insights. The theme "seeking for reassurance" was found after finishing data collection but the theme "creating meaningful moments" was found earlier and was mentioned by every respondent, and although the relationship between client and caregiver is yet described in literature being meaningful to a client is a new theme. Perhaps this is due to the profound disabilities clients in this study had or to the method of this study, focusing only on the caregivers.

Literature also shows in line with seeking for reassurance, uncertainty and fear of the unknown [12]. De Maeyer and Maes describe caregivers who fear things to come even as fear of doing something wrong. Medical practitioners can help reduce uncertainty by explaining circumstances and be present at the ward for psychological support [12].

The relation between direct-caregiver and client with an intellectual disability is described in previous studies. Alignment and involvement are seen as the core of the care giving in caring for persons with an intellectual disability [19]. Sensitivity and attentiveness are necessary to properly interpret signals [20]. Donovan described that nurses knowing their clients are better able to help patients in pain because of their relationship and involvement with the client [11]. Furthermore study results show that it could be hard for direct-caregivers to cope with 
situations that are more complex f.e when client's pain is changing continuously and therefore difficult to diagnose and to treat efficiently $[11,20]$.

Closure of the relation with the client helps directcaregivers to accept the client's death. Kehl describes that several elements contribute could contribute to achieve "a good death": being comfortable, sense of closure, value of the dying person recognized and recognition of impending death [21]. These results confirm the themes described in the present study results. In line with results of other studies [22] the present results underline the importance to achieve a sense of closure for caregivers which seems to lead to a greater sense satisfaction [22]. This can explain why direct-caregivers can appreciate to take this care if the process evolves smoothly.

In this study the death of a child is perceived as intense. This can be explained by the fact that the death of a child is conceptual an unnatural and premature event $[21,23]$. However, these studies consider palliative care in general, not the palliative care of persons with an intellectual disability. The special and complex relationship between client and caregiver can make this perception different.

The results of this study could contribute to enlarge insights about palliative care to people with an intellectual disability, because of the thick description of the experience as described by the fifteen respondents.

The results of this study show direct-caregivers are frequently confronted with their own feeling of insecurity because of having to rely on their own interpretations what constitute good care for their clients. Therefore they need to get reassurance from colleagues, manager and family. They also underline the necessity of having enough time to create meaningful moments with their client and to say goodbye. This above al seems to contribute to their sense of disclosure the relationship with the client.

As the results of the present study show that the relationship between direct-caregiver and client contribute importantly to the quality of care it seems necessary to better understand which characteristics of a relationship. Study based on Participant observation should be undertaken to gain more insight in these aspects. Furthermore studies should be directed describing the experience of direct-caregivers caring for clients with less care needs rather than caring for clients who are severely affected.

\section{CONCLUSIONS}

Direct-caregivers caring for a client with an intellectual disability who is terminally ill, experience an intense period of insecurity and also a special period meaningful when caring a dying client with intellectual disabilities. Their relationship with the client makes them to be more able to strive for client's comfort.

Direct-caregivers find it difficult to see the client not being comfortable. Communication and support from medical practitioners and managers can help them to find the reassurance they need. Education of direct-caregivers needs to focus on medical and nursing backgrounds such as withholding food and knowledge of differences between palliative sedation and euthanasia.

\section{ACKNOWLEDGEMENTS}

We thank direct-caregivers who participated in the study for their efforts in reporting their experience. We also thank the organization where the study took place for the collaboration. And we thank Janneke de Man, MSc for her support during the study process.

\section{REFERENCES}

[1] McCallion, P. and Nickle, T. (2008) Individuals with developmental disabilities and their caregivers. Journal of Gerontological Social Work, 50, 245-266. http://dx.doi.org/10.1080/01634370802137959

[2] Ellison, N.M. and Rosielle, D. (2008) Palliative care for adults with developmental disabilities \#192. Journal of Palliative Medicine, 11, 1262-1263. http://dx.doi.org/10.1089/jpm.2008.9830

[3] Li, S. and Ng, J. (2008) End-of-life care: Nurses' experiences in caring for dying patients with profound learning disabilities - A descriptive case study. Palliative Medicine, 22, 949-955.

http://dx.doi.org/10.1177/0269216308096905

[4] Friedman, S.L., Choueiri, R. and Gilmore, D. (2008) Staff carers' understanding of end of life care. Journal of Policy and Practice in Intellectual Disabilities, 5, 56-64. http://dx.doi.org/10.1111/j.1741-1130.2007.00142.x

[5] Watchman, K. (2005) Practitioner-raised issues and endof-life care for adults with down syndrome and dementia. Journal of Policy and Practice in Intellectual Disabilities, 2, 156-162. http://dx.doi.org/10.1111/j.1741-1130.2005.00026.x

[6] Tuffrey-Wijne, I. (2002) The palliative care needs of people with intellectual disabilities: A case study. International Journal of Palliative Nursing, 8, 222-232.

[7] de Haan, K. and van Rossum, N. (2010) Richtlijn: Palliatieve zorg voor mensen met een verstandelijke beperking. Landelijke richtlijn versie 1.0. Redactie Palliatieve Zorg: Richtlijnen voor de Praktijk/IKPallialine/VIKC.

[8] Tuffrey-Wijne, I., Hogg, J. and Curfs, L. (2007) End-oflife and palliative care for people with intellectual disabilities who have cancer or other life-limiting illness: A review of the literature and available resources. Journal of Applied Research in Intellectual Disabilities, 20, 331344. http://dx.doi.org/10.1111/j.1468-3148.2006.00350.x

[9] Ng, J. and Li, S. (2003) A survey exploring the educational needs of care practitioners in learning disability (LD) settings in relation to death, dying and people with learning disabilities. European Journal of Cancer Care, 12, 12-19. 
http://dx.doi.org/10.1046/j.1365-2354.2003.00323.x

[10] Folkestad, H. and Folkestad, L. (2008) The sociology of acceptance revisited: "There must have been something because I grieve so !". Journal of Intellectual \& Developmental Disability, 46, 427-435. http://dx.doi.org/10.1352/2008.46:427-435

[11] Donovan, J. (2002) Learning disability nurses' experiences of being with clients who may be in pain. Journal of Advanced Nursing, 38, 458-466. http://dx.doi.org/10.1046/j.1365-2648.2002.02207.x

[12] De Maeyer, J. and Maes, B. (2010) Palliatieve zorg voor mensen met ernstige meervoudige beperkingen. Eindrapport. Centrum voor Gezinsen Orthopedagogiek KULeuven \& Multiplus, Leuven.

[13] Holloway, I. and Wheeler, S. (2002) Qualitative research in nursing. Blackwell Science, Oxford.

[14] Charmaz, K. (2006) Constructing grounded theory. A practical guide through qualitative analysis. Sage Publications, London.

[15] Creswell, J.W. (2007) Qualitative inquiry \& research design. Sage Publications, California.

[16] Verbi (1998) Winmax. www.winmax.de

[17] Došen, A. (2005) Psychische stoornissen, gedragsproblemen en verstandelijke handicap. Een integratieve benadering bij kinderen en volwassenen. Van Gorcum, Assen.

[18] Woittiez, I. (SCP) and Ras, M. (SCP) Hoe vaak komt een verstandelijke handicap voor? Volksgezondheid Toekomst
Verkenning, Nationaal Kompas Volksgezondheid. RIVM. 1, Bilthoven.

[19] Schuengel, C., Kef, S., Damen, S. and Worm, M. (2010) "People who need people": Attachment and professional caregiving. Journal of Intellectual Disability Research, 54, 38-47.

http://dx.doi.org/10.1111/j.1365-2788.2009.01236.x

[20] Stoffelen, J.M.T., Buntinx, W.H.E., Wagemans, A.M.A., van Schrojenstein Lantman-de Valk, H.M.J. and Curfs, L.M.G. (2008) Palliatieve zorg voor mensen met een verstandelijke beperking in de praktijk. Een Verkennend Onderzoek. NTZ, 1, 20-33.

[21] Kehl, K.A. (2006) Moving toward peace: An analysis of the concept of a good death. The American Journal of Hospice \& Palliative Care, 23, 277-286. http://dx.doi.org/10.1177/1049909106290380

[22] Kwak, J., Salmon, J.R., Acquaviva, K.D., Brandt, K. and Egan, K.A. (2010) Benefits of training family caregivers on experiences of closure during end-of-life care. Journal of Pain and Symptom Management, 33, 434-445. http://dx.doi.org/10.1016/j.jpainsymman.2006.11.006

[23] Graham, R.J. and Robinson, W.M. (2005) Integrating palliative care into chronic care for children with severe neurodevelopmental disabilities. Journal of Developmental And Behavioral Pediatrics, 26, 361-365. http://dx.doi.org/10.1097/00004703-200510000-00004 